\title{
A brief comparison of old erotic paintings in the Far East
}

\author{
Won Whe Kim * \\ Department of Obstetrics and Gynecology, Pusan National University School of Medicine, Busan, Korea
}

\begin{abstract}
Sexuality brings similar physical and emotional manifestations but shows many cross-cultural variations. Three East Asian countries, China, Japan, and Korea, have been under somewhat similar cultural backgrounds almost for the last two thousand years mainly by being influenced by the so-called Confucian ideology. That applies to the art including paintings, sculptures, etc. However, the characteristics of the erotic paintings differed so much in many aspects.
\end{abstract}

Keywords: Sexuality, History, Culture

\section{Neo-Confucian Culture}

In the Asia Pacific region, people have been living under the influence of Confucianism exceed that of Hinduism, Buddhism, Taoism, Shintoism, in their order.

Confucianism that had been so much influenced by human sexuality in this part of the world was China rooted ideology or philosophy and Chinese, Japanese, Korean, and Vietnamese have been under these cultural backgrounds for thousands of years. Confucius was born in China 552BC and he had so many followers and still has. His idea was remodeled in the 12th century during the Song dynasty mainly by Zhu Xi with a mixture of Confucianism and Taoism and this new teaching is called neo-Confucianism. In(仁), mercy or gentleness was teaching by Confucius, but the principle of a new idea was $\mathrm{Li}($ 理), which emphasizes more on rationality. We can say In comes from one's heart but Li comes from one's brain. The main teachings of Zhu Xi were as fol- lows: filial piety (孝道), shame as a method of reinforcing expectations and proper behavior(謙遜), self-control (自制心), emphasis on consensus(與論重視), fatalism(宿命 主義), inconspicuousness(自己卑下).

The effect of this ideology to the sexual attitude was that of negativism. Human sexuality was very much tabooed, and women's right including sexual rights was almost negligible. For thousands of years in East Asian countries, male dominant ideas were the rule. Women were only to raise their children, support their family in many ways including not only ordinary house works but also hard labor in agriculture.

Women's duty and conditions were as follows: 'Three rules of obedience for women(三從之道)' 1 ) to obey to her father before marriage, 2) to obey to her husband after marriage, 3) to obey to her son after her husband 's death and 'Seven valid reasons to drive out one's wife( $七$ 去之惡)'：1) not obeying to her parents-in-law, 2) no son, 3) like sex, 4) jealousy, 5) bad illness, 6) talking too

Manuscript received February 11, 2019; Accepted February 20, 2019.

*Corresponding author: Won Whe Kim. Department of Obstetrics and Gynecology, Pusan National University School of Medicine, Busan 49241 , Korea.

Tel: +82-2-6203-0380, E-mail: wwkim@pusan.ac.kr

(C) Copyright 2020 Korean Association for Sexology

This is an Open Access article distributed under the terms of the Creative Commons Attribution Non-Commercial License (http://creativecommons.org/licenses/by-nc/4.0/)

which permits unrestricted non-commercial use, distribution, and reproduction in any medium, provided the original work is properly cited. 
much, and 7) stealing. 'A woman inferior to a man (男尊 女卑), 'Boy and girl not together after the age of 7 (男女 七歲不同席)' were some of many examples of these kinds. Now, of course, things have been changed so much that women seem to enjoy more rights than men but yet, I believe, we need more time to be equal sexually.

Fortunately, however, Taoism that coexisted with Confucianism allowed some positive aspects when it comes to the attitude toward sex. The Chinese letter 'Tao(道)' is a combination of the head(首) and running (走) that differs a lot from the main ideology. Probably original meaning was 'to follow what your head orders.'

Anyway, in Taoism, meditation and inward-looking are important. I believe it was closer to Buddhism and Hinduism than Confucianism. No matter what kind of religion one has, most of the Asian countries are under some influence of Buddhism in that sex is not that much tabooed.

Sexual act depends on value, desire, and ability but what is most important is the value. Culture is the lens through which motivation occurs and influences to one's sexual decisions. That is why the religious background is so important.

Before Confucian ideology in Korea, our ancestors lived in a rather free sex society. A modern looking dildo was excavated recently from the old capital of the Shilla Dynasty. They had many clay Figures of sexual intercourse during the same era (Fig. 1).

It was in $16^{\text {th }}$ century in Korea when neo-Confucian-

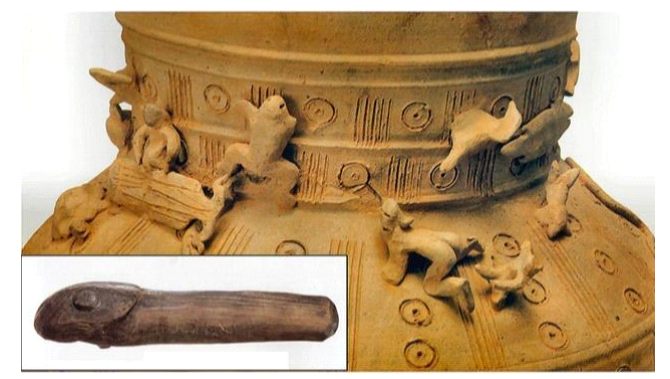

Fig. 1. Clay pottery with interesting sexual figures and well-preserved dildo of Shilla dynasty (57BC-935AD). ism governed strictly as far as sexual matters are concerned.

Chinese erotic painting focused more on physical sex postures and deal with the amusement of imperial family or upper class while Japanese ones developed their unique characteristics through the collaboration with Ukio-e(浮世繪, floating-world picture), in that the coloring, exaggeration of sexual organ, and the special shape of clothing and furniture fascinate the people.

Korean erotic art was formerly influenced by China's Ming dynasty eroticism, but in the 18th century, Chosun (1392 to 1910), the last Korean dynasty, erotic art, was able to be developed to its own identity. They were very unique compared to Chinese or Japanese paintings and revealed sexual custom of those days through its $\mathrm{de}^{-}$ scription of various social classes and situations. Korean erotic paintings rather show the real lives of ordinary people of those days and make you feel warm and quite sensitive as well as a little humor.

\section{History of Erotic Paintings}

Records are indicating that in 1040BC, Dalgi(妲己) and King Chu(紂), the famous tyrant in Chinese history, enjoyed erotic paintings on the folding screen of their bedroom. About one thousand years later, in 100BC to be exact, King Kwangchun of the Han dynasty also was known to enjoy erotic paintings as well. During the Tang dynasty(618 906), folding screens at most brothel had these kinds of paintings were popular but it was during the Ming dynasty(1570 1640) when it was really flourished. They start to produce by 'wood printing and coloring technique.' 'Secret book for the couples(鴐鷽祕 譜),' wood-printed one published in 1642 was known to be the best of those kinds (Fig. 2).

Numerous records of similar kinds appear in various history books, but unfortunately, no erotic painting of 


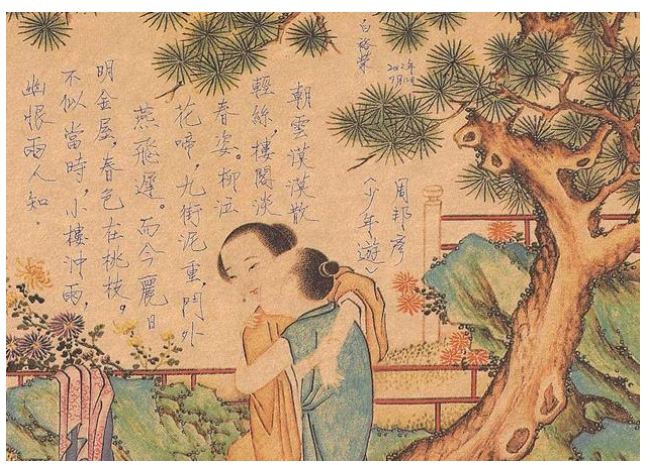

Fig. 2. From 'Secret book for the couples', wood-printed book published in 1642 during Ming dynasty.

them was remaining. The 1sterotic pictures still left is that drawn during in $1120 \mathrm{AD}$, Northern Song era. In there, the already binding feet of the lady appears (Fig. 3).

The reason people kept these kinds of erotic materials probably has three reasons: 1) for incantation that is to treat sexual dysfunction or to attract the opposite sex, 2) sex education especially to encourage sooner pregnancy at the royal family, and 3) aphrodisiac purpose of promoting sexual desire of partner or him or herself.

\section{Characteristics of Paintings}

Though lived under similar cultural background, the characteristics of erotic paintings were quite different. Followings are some examples:

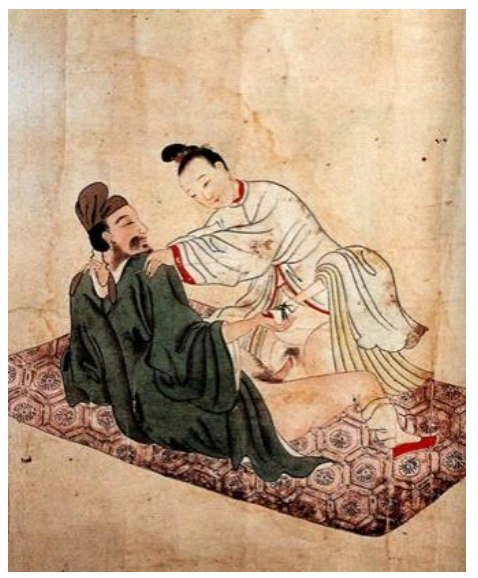

Fig. 3. First erotic picture of China still left. Drawn during 1119-25AD Northern Song era. Binding feet of the lady already appear.

\section{Characteristics of Chinese paintings}

1) Somewhat sex educational

2) Painting focused more on different physical sex postures (Fig. 4)

3) Deal with the amusement of the imperial family or upper class.

4) Usually with formal dresses

5) Women's bound feet always covered

6) Paraphilia, S\&M, bestiality, homosexual, group sex, oral, atypical positions all appear (Fig. 5)

\section{Characteristics of Japanese paintings}

1) Erotic paintings were called 'oko-e(痴繪)' in the 11-12 century, and then, 'ehon(酆本), irohon(色本) during the Edo era.

2) Always shows a member of the upper class with formal clothing and nice furniture, etc. (Fig. 6).

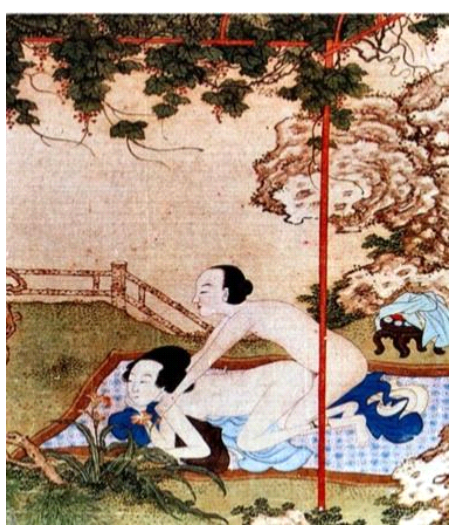

Fig. 4. Chinese painting focused more on different physical sex postures. Ching dynasty, late $18^{\text {th }}$ century.

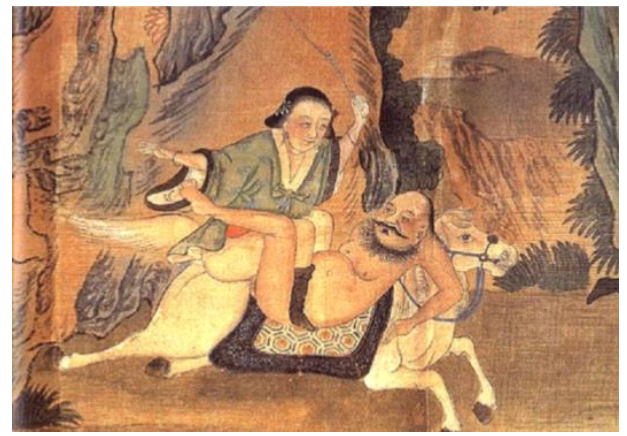

Fig. 5. Sex on the horse. Silk painting. Early Ching dynasty. Woman on top and whipping. 
3) Genitalia is very much exaggerated, especially in the male penis. Most likely, it was because of better incantation and to bring fortune through it. Female pubic hairs were drawn individually and took most of the time (Fig. 7). The unrealistically large penis was already present in the 12thcentury. One of the remaining pictures is 'Comparison of penile size(陽物くらべ-鳥呵 僧正, 1053-1140, Late Heian era monk)', the first Japanese erotic painting on paper (Fig. 8). The first picture drawn on the stone was left at Horyuji(法隆寺) temple in Nara and is known to be that of $8^{\text {th }}$ century.

4) 'Ukio-e' - Developed unique characteristics of usual custom moral painting. However, there were many erotic ones of these kinds. Sometimes, dealing with kabuki world as well as a brothel. Hokusai Katsushika (1760-1849), a famous Ukio-e painter, has drawn many masterpieces of eroticism (Fig. 9).

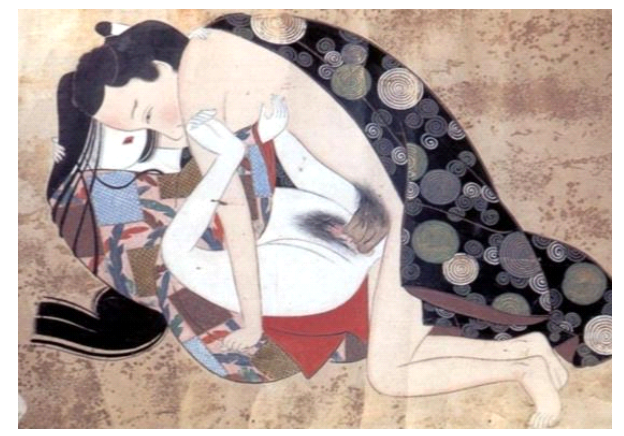

Fig. 6. Exaggerated and detailed sex organs are not realistic but most likely to add artistic effects. They thought too realistic picture were boring. 17c Japan.

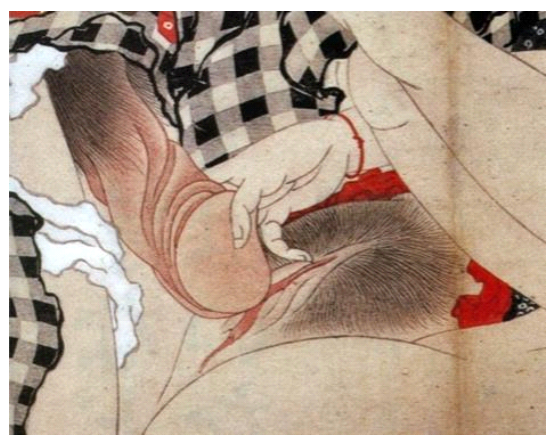

Fig. 7. Pubic hairs drawn individually. This part took most of the time in painting.

\section{Characteristics of Korean paintings}

Unlike China or Japan, Korea has kept very few of these kinds, and left ones are those of all after the $16^{\text {th }}$ century. Unlike China and Japan, no record of erotic woodcut paintings was found in Korea (Fig. 10). It is probably because: 1) people's narrow-mindedness toward sex, 2) there was no official publication, 3) many artistic valuable things are still hidden in the home by

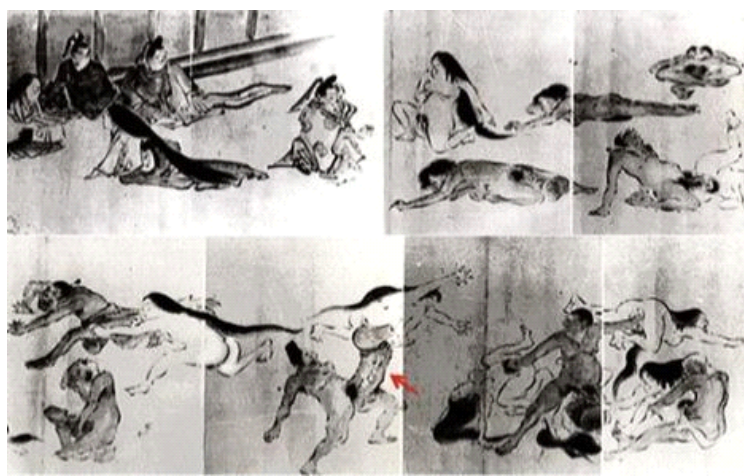

Fig. 8. Comparison of penile size(陽物，〈らべ - 鳥炣僧正10531140, Late Heian era monk). The first Japanese erotic painting on paper. Red arrow shows big penis.

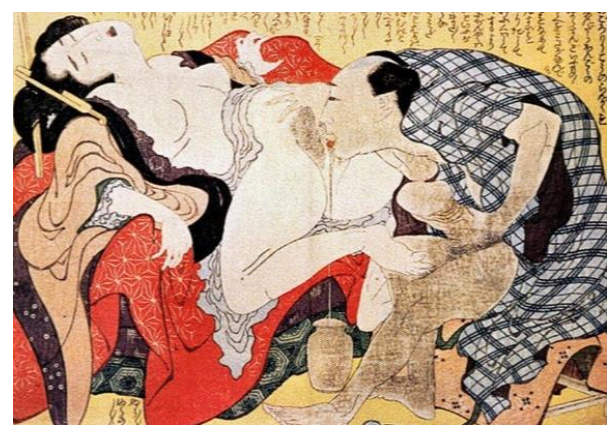

Fig. 9. Collecting vaginal secretion into a jar. Hokusai, 1823.

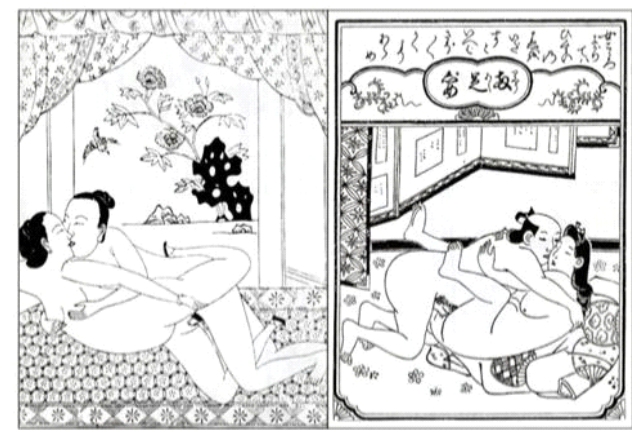

Fig. 10. The first woodcut paintings of China (left, 1600) and Japan (right, 1678). In spite of many decades of difference, they are quite similar. Note feet binding and Japanese characters. 
collectors, 4) and shy to announce they have such a thing.

Most of them were drawn privately by painters or amateurs and were hidden in the home of the collectors. This is probably why Korean erotic paintings are seldom seen nowadays. We never had woodcut or lithography as in China or Japan. They were drawn privately by painters or amateurs and were hidden in the home of the collectors. And it was only after political and economic stability set in during king Young-Jo(1724-1776) when erotic paintings began to be produced with an expansion of wealthy classes. There were plenty of Chinese paintings imported during this era as well.

\section{Characteristics Comparable to Chinese}

\section{and Japanese Ones are as Follows:}

1) Before the early 18thcentury, Korean paintings were just symbolic (Fig. 11). Korean erotic paintings make you feel warm and quite sensitive and usually have a little humor.

2) Korean erotic art was known to be influenced by China's Ming dynasty eroticism. But in 18th century, Chosun erotic art was able to develop to its own identity.

3) The Korean paintings are not to show any sex techniques but usually reflect the nature of Yin and

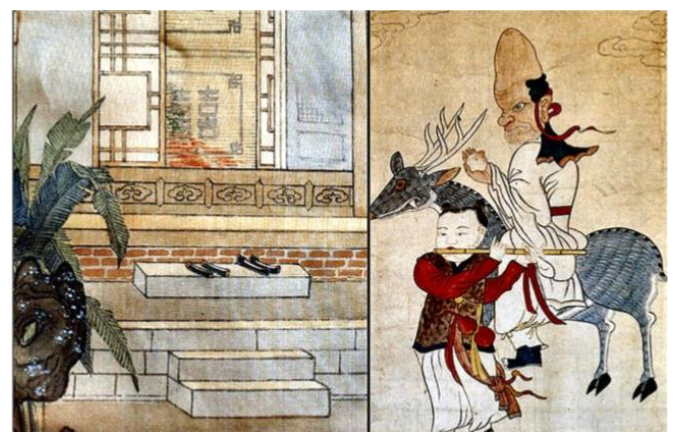

Fig. 11. Most of the early Korean erotic paintings were symbolic as on the left. In the right, you can easily remind male penis from man's bolded head and female genitalia from a peach in his hand.
Yang, male and female on the same plane (Figs. 12, 13).

4) Korean painters didn't seem to focus on the sexual act itself and tried to show more. They do not show just sexual positions or similar kind but reflect the nature of man and woman. Through the Taoistic viewpoint of the universe, Korean eroticism displays completeness through the combination of literary, artistic style, common naivety and even human warmth (Fig. 14).

5) Korean erotic paintings reveal the sexual custom of those days through its description of various social classes and situations. Also, in there, one can see the real-life of those days.

There are many erotic folk-drawings(民畫) by amateurs left as well, and their names are not known. Unlike with professional ones, there is not much artistic value

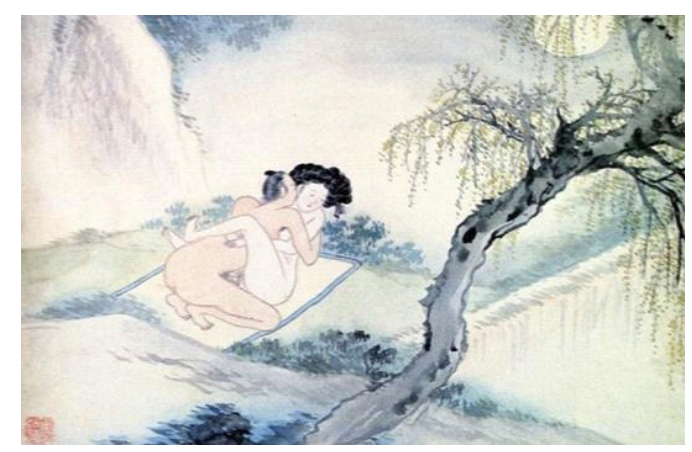

Fig. 12. Korean painter, Kim Hong Do(金弘道, 1745-1806). The moon and rather misty branches of willow tree make this erotic painting look more like a landscape picture. The poetic landscape background goes well with the sexual union. The very thin legs of the woman might mean her 'let-go'.

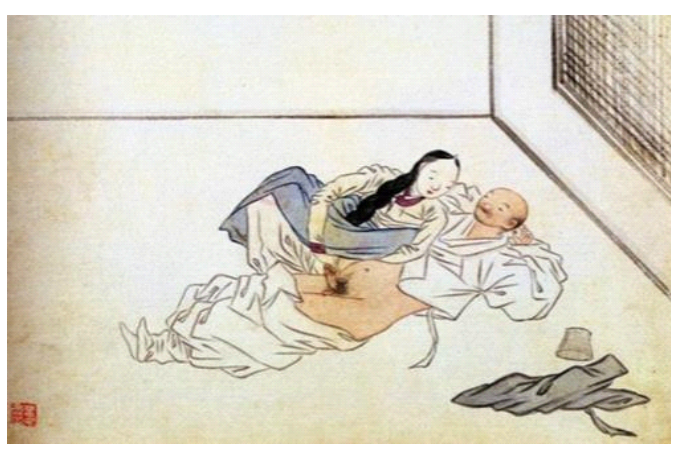

Fig. 13. Shin Yoon Bok(申潤福, 1758 ? 德園). Braided hair means she is not married. Maybe she is a maid came with a noble woman. No furniture as it is a temple room. By looking at the monk's expression, she is seducing him. He enjoys but is quite frustrated. Left hand fingers tell the story. 


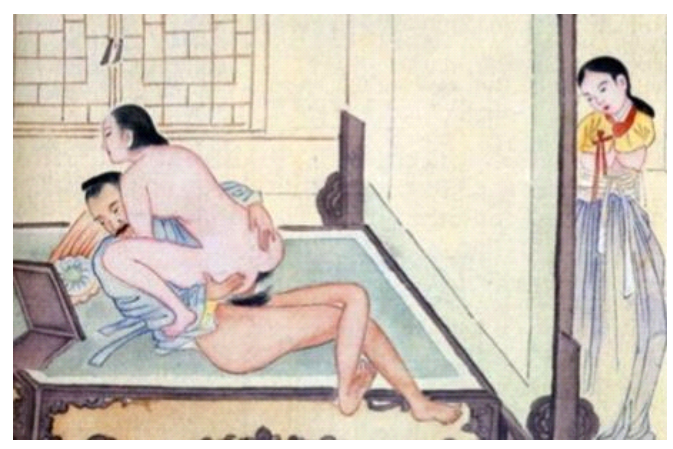

Fig. 14. 최우석(崔禹錫 1899 1965) Middle-aged man and woman are making love one bed while a housemaid peeps in on the love affair behind the screen. The man is looking his own sex affair into the mirror.

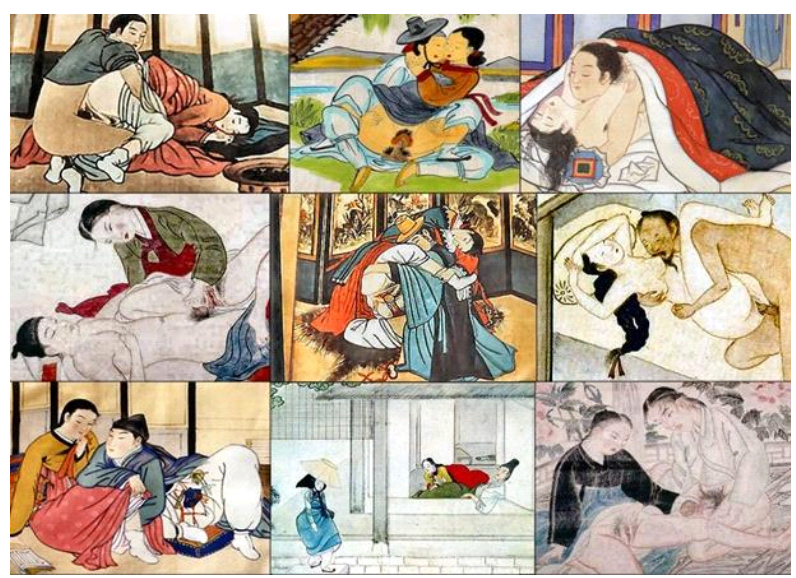

Fig. 15. Collections of folk drawings. Painters are not known. Though their artistic value are variable, we can still learn a lot from their way of livings including furniture, clothes, beddings, etc. but yet, with the expressions of the couple, you can feel humanity and humor instantly.

\section{References}

1. Yoon H. R., The Sex of Korea, Taebaek, 1993.

2. Kim W. W., Sex History of Korea, 3rd ed, Booklab, 2017.

3. Fukuda, K., Ukioe of the World, Best, 2004.

4. Shincho, G., Hokusai's Erotica, Shincho, 2002.

5. Sakaguchi, W. et al, Yamamura's Ukioe, Best Mook Series, 1991.

6. Kim, W. W., The History of Sex in Korea, Sex of Koreans, Kor Androl Assoc, 2013.

7. Kim, W. W., Comparison of Erotic Paintings between Hong Do Kim and Yoon Bok Shin, Unpublished, 2008.

8. Block jys 5400, World of Erotic Paintings during Chosun Dynasty, Basic Folder, 2005. 